\title{
A systematic review and meta-analysis of students' study habits in Iranian Universities of Medical Sciences
}

\author{
ABDOLREZA GILAVAND ${ }^{1, \text { A }}$, YASAMAN EMAD², в \\ ORCID ID: 0000-0003-4340-1843 ORCID ID: 0000-0003-0093-149x \\ ${ }^{1}$ Department of Community Medicine, School of Medicine, Ahvaz Jundishapur University of Medical Sciences, \\ Ahvaz, Iran \\ ${ }^{2}$ Department of Psychological Medicine, School of Medicine, Faculty of Medical and Health Sciences, University \\ of Auckland, Auckland, New Zealand
}

A - Study Design, B - Data Collection, C - Statistical Analysis, D - Data Interpretation, E - Manuscript Preparation, F - Literature Search, G - Funds Collection

Summary Background. Due to the role of correct habits in students' academic progress, this study is aimed at evaluateing students' study habits in Iranian medical universities.

Material and methods. Data collection method in this study was a systematic review and meta-analysis based on searches for articles published on reputable Iranian and international sites for words such as "study habits," "students," "University of Medical Sciences," and "Iran"; it was conducted without any time limit. It used a standard questionnaire of 45 study habits by Palsane and Sharma (PSSHI). Also, in the dataj analysis, computer software R version 3.6.3 was used to estimate the average score of students' study habits. Results. In the present study, 13 articles were reviewed, as a result of which 2,665 students who were studying at one of the Iranian medical universities from 2006 to 2018 were assessed. The overall score for students' study habits was 49.03 out of a maximum score of 90. Similarly, eight areas of students' study habits were calculated separately: time allocated was 5.61 out of a maximum score of 10; physical conditions was 6.94 out of a maximum score of 12 ; reading capability was 14.8 out of a maximum score of 16 ; note-taking was 3.17 out of a maximum score of 6 ; learning motivation was 6.93 out of a maximum score of 12; memory was 4.61 out of a maximum score of 8; taking exams was 9.92 out of a maximum score of 20; and health was 3.23 out of a maximum score of 6.

Conclusions. The overall score of the students' study habits was moderate and the score for "taking exams" was the weakest. Consequently, bearing in mind that these areas of study are related to people's health, it is probable that these students will have study habits that are better and higher than average; the Ministry of Health, Treatment and Medical Education of Iran should consider this point. Medical universities can assess their students' study habits before they enroll in the university, and if necessary, improve these habits by performing some educational interventions, such as organizing training courses, and using mobile educational applications, etc. Key words: medical students, systematic review, meta-analysis, Iran.

Gilavand A, Emad Y. A systematic review and meta-analysis of students' study habits in Iranian Universities of Medical Sciences. Fam Med Prim Care Rev 2021; 23(3): 363-371, doi: https://doi.org/10.5114/fmpcr.2021.108204.

\section{Background}

One of the main objectives of universities is the improvement and development of students' academic performance, which is influenced by many factors; one of them is study habits. In recent years, due to innovation in information technology, concepts such as studying, reading, and learning have been redefined [1]. Studying can be defined as purposeful reading with note-taking, which is often complemented by reading, observing, asking questions, listening, thinking, and expressing opinions [2]. One group of researchers defines study skills as a cognitive activity that simplifies the process of storing, retrieving, and using knowledge and learning [3]. Another group perceives it as a way to encode, store, maintain, restate, and use information effectively [4]. Study skills can be changed through educational interventions, and today digital technologies and virtual social networks are also used as important options that improve student learning [5]. Study approaches are divided into two types: surface and deep. Among the surface approaches, one can mention mental retrieval, repetition and review, which help to maintain information in short-term memory, while the deep approaches include imaging, expanding, and encoding content, which leads to long-term information retention [6]. The results of studies conducted in Iran [7, 8], Saudi Arabia [9,
10], Turkey [11], Pakistan [12], the Philippines [13], Spain [14], England [15], and the United States of America [16] have suggested that selecting the right study methods can lead to higher academic achievements or enhance the learning process.

One of the significant tools for assessing students' study habits is the Palsane and Sharma Study Habit Inventory (PSSHI), which has been used extensively in Iran to assess students' study habits at medical universities [17-28]. Studies have shown that the quality of educational services provided by Iranian medical universities is not as high as students expect [29]. Successful students are familiar with correct study methods and can use them to store large volumes of material easily in their minds without spending much time. Of course, each student has his or her own study style that may even be a source of differences despite the same age and cultural and religious backgrounds. Students are aware of how proper scientific study skills can lead to their academic progress and success, and that ignoring these learning methods can lead to an educational deficit. Therefore, considering the role that correct habits play in students' academic progress and the fact that these fields of study are among the most demanded fields in Iran as well as being related to people's health, medical students are expected to have better study habits than other students. Consequently, it is necessary to examine the students' strengths and weaknesses in the area of correct reading; and in line with it, their competencies 
must be strengthened and their possible shortcomings must be eliminated. Numerous studies in Iran have examined the study habits of medical students. So far, no systematic study or meta-analysis has evaluated the study habits at medical universities. Consequently, this research, while comparing the study habits of students at universities of medical sciences in Iran, can help compare them within different areas.

\section{Material and methods}

\section{Search strategies}

Data collection in this systematic review research (meta-analysis) was done in January 2020 by searching for articles published in reputable Iranian and international sites (including SID, MAGIRAN, Iranmedex, GoogleScholar, CINAHL, Embase, PubMed, Scopus, and Science Direct) and by searching for the words "study habits," "students," "University of Medical Sciences," and "Iran" without any time limit. In this search, only Iranian articles in Persian and English and studies done in Iran were taken into account. There was no time limit on the selection of articles. The search was conducted by two authors, and the articles whose subject was the review of students' study habits based on the standard questionnaire of 45 study habits of Palsane and Sharma (PSSHI) in one of the universities of medical sciences in Iran were selected. The primary search of the articles was done by two authors separately; after eliminating any overlaps, the titles and abstracts of the articles were reviewed. Several articles were removed at this stage. The full text of the selected articles were then reviewed. At this stage, several irrelevant and weak articles were dropped. So, in the preliminary search, 143 articles were obtained. Of these studies, 65 articles were reviewed and, ultimately, the full text of 13 articles entered into the final review. Two authors analyzed the full text of each article and discussed it until a consensus was reached.

\section{Inclusion and exclusion criteria}

In the current study, only quantitative, original articles in which students' study habits were among the main variables were examined; of course only study habits of students of Iranian medical universities and articles based on the standard PSSHI questionnaire were investigated.

In this study, short articles, letters to the editor, review articles, and quality articles were excluded from the study.

\section{Study tools}

One of the most significant tools for measuring students' study habits is the Palsane and Sharma Study Habit Inventory (PSSHI). It has been used extensively in Iran to evaluate the study habits of medical university students [17-28]. This questionnaire consists of eight components: time budgeting (five questions), physical conditions for study (six questions), reading ability (eight questions), note-taking (three questions), learning motivation (six questions), memory (four questions), taking examinations (ten questions) and health (three questions). Based on the questionnaire's instructions, a score of 2 is given to the answer "always or most of the time," a score of 1 is assigned to "sometimes," and zero points are allocated to "rarely or never," so the minimum total score is zero and the maximum score is 90. The higher the score, the better the study habits. The eight areas of this questionnaire are also scored separately; time budgeting (0-10), physical conditions $(0-12)$, reading ability $(0-16)$, note-taking (0-6), learning motivation (0-12), memory (0-8), taking exams (0-20), and health (0-6). Finally, the total score of students' study habits is classified into three types: undesirable study habits (a score of less than 30 ), average or relatively desirable habits (a score of 31-60), and desirable habits (a score of 61-90) [19].

\section{Evaluating the quality of articles}

The Strobe checklist was used to evaluate the quality of the articles. The articles were arranged in order of importance and relevance to the topic, and parts of each article that could be used were identified. The weaknesses and strengths of each article were noted and comprehensive conclusions were drawn. Studies that measured students' study habits and simultaneously had appropriate research characteristics, such as specific validity and reliability, optimal sampling method, and results related to the objectives of the subject were included in the study. After studying all the articles, 13 articles that investigated the students' study habits in one of the Iranian universities of medical sciences based on the PSSHI finally entered the study. The final articles are presented and described according to selected features.

\section{Data extraction}

The distinctive features of the research were identified using a checklist designed by the researchers. This checklist included the names of the authors, the year of the study, the number of students, the place of study, and the most important results of the selected articles. Based on the input criteria, the two authors independently examined the data. In the absence of agreement between the authors, a third author intervened.

\section{Research findings}

In the preliminary search, 143 articles were found. After deleting duplicate publications, 65 related articles were reviewed, in which 13 local and national studies, including 11 done at Iranian universities of medical sciences, were selected, after excluding the studies that did not meet the required conditions. The details of the article selection method are shown below (Figure 1).

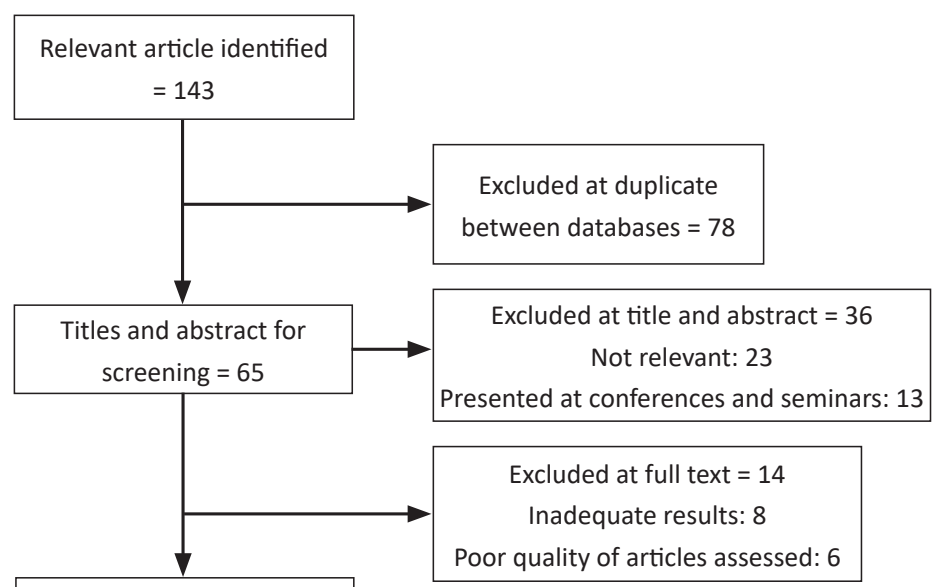

Full text selected $=29$

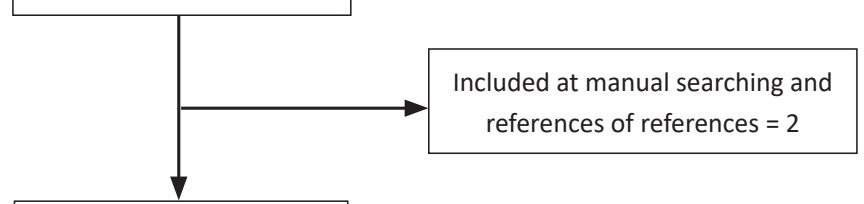

Total included articles $=13$

Figure 1. Flow diagram for study selection

Lastly, the opinions of 2,665 people who were studying in one of the Iranian universities of medical sciences from 2006 to 2018 were analyzed in this study. From these articles, five were written in English and eight were written in Persian (Table 1). 


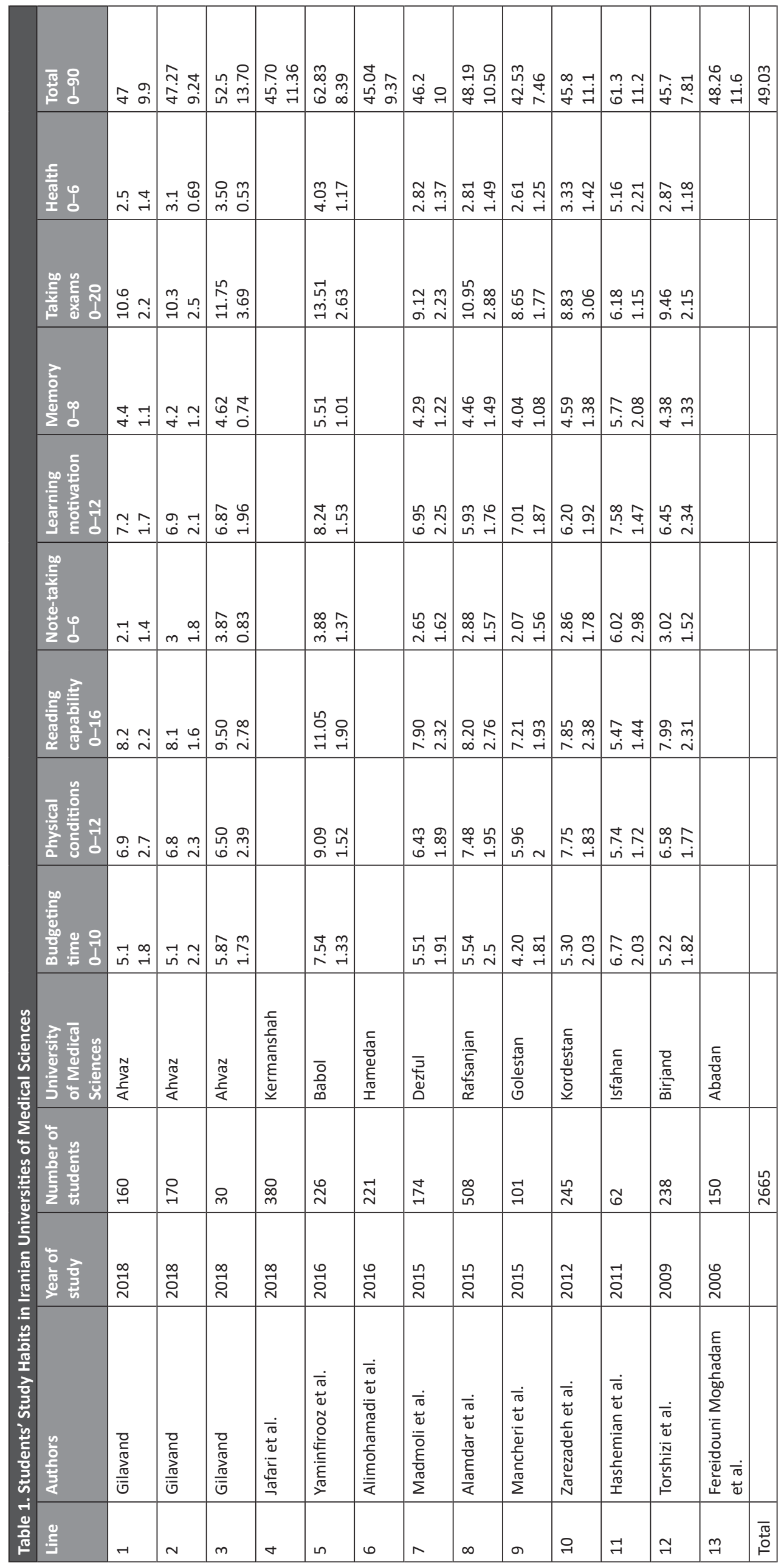




\section{Ethical approval}

Full ethical approval was obtained from the National Agency for Strategic Research in Medical Education (grant No. 960437).

\section{Data analysis}

In the data analysis, computer software R version 3.6.3 was used to estimate the average score of students' study habits. The $I^{2}$ index was also used to evaluate the heterogeneity of the studies. Since heterogeneities were found among the studies, the model of random effects ( $P$ statistic of $Q>0.05$ or $I^{2}>50 \%$ ) was used with a confidence interval of $95 \%$. Since only $50 \%$ of publication bias can be detected in a funnel plot, the Egger test was used to evaluate the possibility of publication bias. The significance levels for the total score of study habits and the eight areas - time budgeting, physical conditions, reading ability, note-taking, learning motivation, memory, taking examinations and health - were $p=0.84, p=0.20, p=0.11, p=0.46$, $p=0.53, p=0.46, p=0.75, p=0.74$, and $p=0.59$, respectively, which showed the possibility of statistical bias in the total score of study habits and the fact that none of the domains was statistically significant. A total of 13 eligible studies entered the systematic review and the meta-analysis phase for us to calculate the general mean of study habits. However, as we needed to calculate the eight study habits, three articles by Jafari et al. [19], Alimohammadi et al. [21] and Fereidouni Moghadam and Cheraghian [28] did not enter the meta-analysis stage due to incomplete information (non-reporting of standard deviation).

\section{Results}

In numerous studies, the highest overall average scores of study habits (62.83) was reported in the study of Yaminfirooz et al. [20], carried out in 2016 among students of Babol University of Medical Sciences in northern Iran, whereas the lowest overall average score for study habits (42.53) was reported in the study of Mancheri et al. [24] conducted in 2015 among the students of the Golestan University of Medical Sciences in northern Iran. The combined meta-analysis or estimation of the mean effects was obtained from the analysis of 13 articles $(52.34,45.72: \mathrm{Cl}$ 95\%) and was 49.03 (Figure 2).

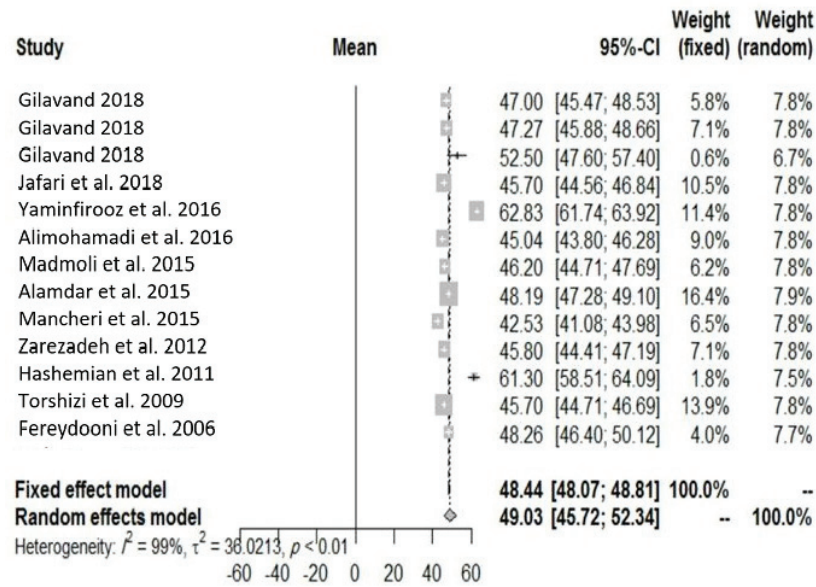

Figure 2. Mean of students' study habits in Iranian medical universities

\section{Time budgeting}

Time budgeting investigates factors such as the students' daily study time, homework time, rest time, and time management while studying. In several studies, the highest mean of the time management area was reported in Yaminfirooz et al.'s

study [20], done in 2016 among students of Babol University of Medical Sciences in northern Iran, with a value of 7.54; the lowest average was reported in two studies done by Gilavand [17] in 2018 among students of Ahvaz Jundishapur University of Medical Sciences in the southwest, with a value of 5.10. The combined meta-analysis or combined estimate of the mean effects was obtained by studying 10 articles $(6.31,4.92$ : $\mathrm{Cl} 95 \%)$ and was calculated as 5.61 (Figure 3 ).

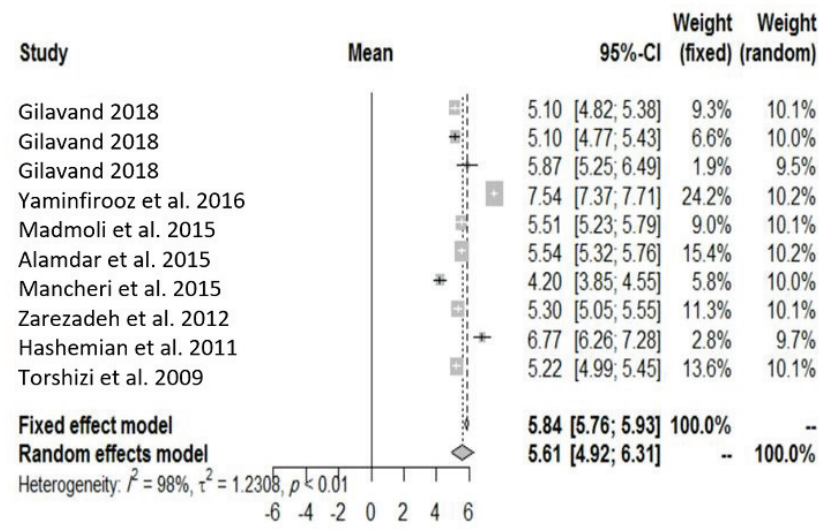

Figure 3. Mean of students' Time budgeting in Iranian medical universities

\section{Health}

This area can be defined as the students' hope or despair in the event of success or failure on an exam, the students' aspiration to follow the study habits guidance program if it is adjusted, and get help from professors to study more effectively. The highest average score in the health area was reported in the study by Hashemian et al. [26] carried out in 2011 among students of Isfahan University of Medical Sciences in central Iran, with a value of 5.16, whereas the lowest average health score was observed in the study ofby Gilavand [17], conducted in 2018 among students of Ahvaz Jundishapur University of Medical Sciences in southwestern Iran, with a value of 2.50. The combined meta-analysis or estimation of the mean effects by studying the ten articles was calculated $(3.55,2.92: 95 \% \mathrm{Cl})$ to be 3.23 (Figure 4).

\section{Study}

Gilavand 2018

Gilavand 2018 Gilavand 2018 Yaminfirooz et al. 2016 Madmoli et al. 2015 Alamdar et al. 2015 Mancheri et al. 2015 Zarezadeh et al. 2012 Hashemian et al. 2011 Torshizi et al. 2009

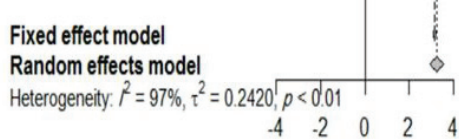

Figure 4. Mean of students' Health in Iranian medical universities

\section{Taking exams}

Taking exams scrutinizes factors such as exam anxiety, students' sleep status during exams, the way and order of answering questions during exams, budgeting time based on the type and number of exam questions, and studying the notes taken before the exam. According to numerous publications, the 
highest average score in this area was reported in the study by Yaminfirooz et al. [20] conducted in 2016 among students of Babol University of Medical Sciences in northern Iran, with a value of 13.51, while the lowest average score was reported in the study by Hashemian et al. from 2011 conducted among students of Isfahan University of Medical Sciences in central Iran, with a value of 6.18 . The combined meta-analysis or estimation of the mean effects as a result of a study of the ten articles (11.81, 8.65: $95 \% \mathrm{Cl}$ ) was calculated as 9.92 (Figure 5).

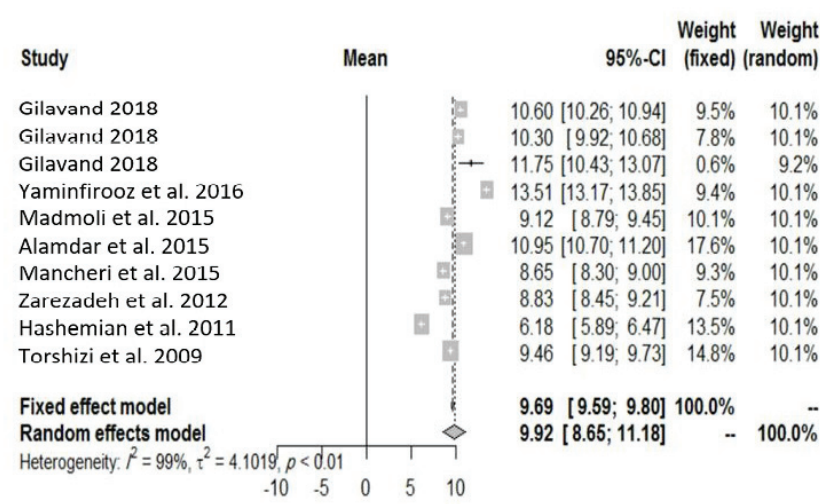

Figure 5. Mean of students' Taking exams in Iranian medical universities

\section{Learning motivation}

Learning motivation analyzes the student's reading materials before they are taught by the teacher, the study at any time the student feels better able to learn, the student's level of regular participation in classes, and his or her willingness to catch up on lessons in which they have problems. In numerous studies, the highest mean score of learning motivation was reported in the study by Yaminfirooz et al. [20], done in 2016 among students of Babol University of Medical Sciences in northern Iran, with a value of 8.24; the lowest mean score of learning motivation was reported in the study by Alamdar et al., performed in 2015 among students of Rafsanjan University of Medical Sciences in the center of Iran, with a value of 5.93. The combined meta-analysis or estimation of the mean effects from studying the ten articles $(7.49,6.37: 95 \% \mathrm{Cl})$ was calculated to be 6.93 (Figure 6).

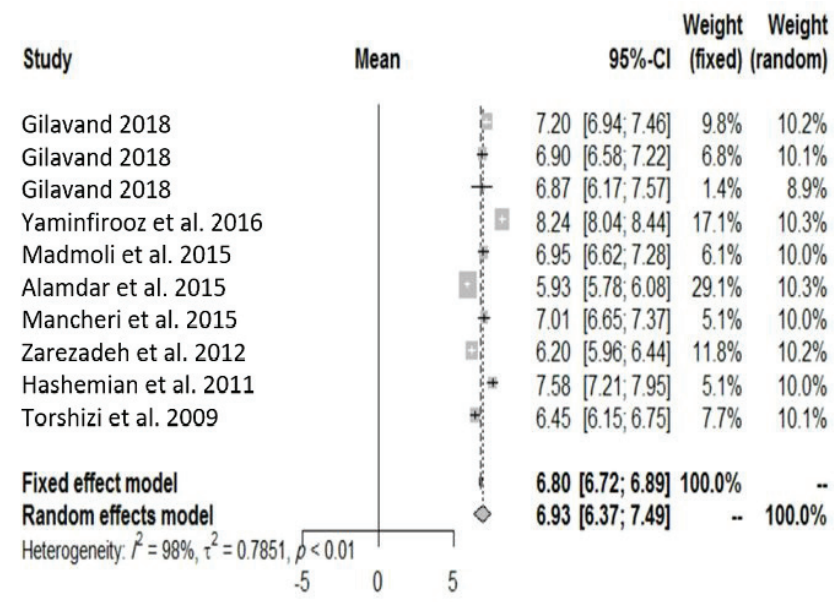

Figure 6. Mean students' Learning motivation in Iranian medical universities

\section{Memory}

Memory investigates the students' ability to recall and review the material studied. Among the numerous studies, the

highest average score of the memory area was reported in the study by Hashemian et al. [26], performed in 2011 among students of Isfahan University of Medical Sciences in central Iran, with a value of 5.77, while the lowest average memory score was reported in Mancheri et al.'s study [24], done in 2015 among students of Golestan University of Medical Sciences in northern Iran, with a value of 4.04. The combined meta-analysis or estimation of the mean effects by studying the ten articles $(4.92,4.29$ : $95 \% \mathrm{Cl}$ ) was calculated as 4.61 (Figure 7).

Study

Gilavand 2018

Gilavand 2018

Gilavand 2018

Yaminfirooz et al. 2016

Madmoli et al. 2015

Alamdar et al. 2015

Mancheri et al. 2015

Zarezadeh et al. 2012

Hashemian et al. 2011

Torshizi et al. 2009

\section{Fixed effect model} Random effects model

$$
\text { Heterogeneity. } \tau^{2}=97 \%, \tau^{2}=0
$$$$
\begin{array}{lllllll}
-6 & -4 & -2 & 0 & 2 & 4 & 6
\end{array}
$$

Mean

Figure 7. Mean of students' Memory in Iranian medical universities

\section{Note-taking}

This area examines whether or not the students take notes during study and the instruction of the teacher. It also reflects whether the notes taken are compared to the original text of the textbook. From numerous studies, the highest mean score of the note-taking area was reported in the study done by Hashemian et al. [26] in 2011 among students of Isfahan University of Medical Sciences in central Iran, with a value of 6.02; the lowest mean of scores was found in the study by Mancheri et al. [24], carried out in 2015 among students of Golestan University of Medical Sciences in northern Iran, with a value of 2.07. The combined meta-analysis or estimation of the mean effects by studying the ten articles $(3.59,2.75: 95 \% \mathrm{Cl}$ ) was 3.17 (Figure 8).

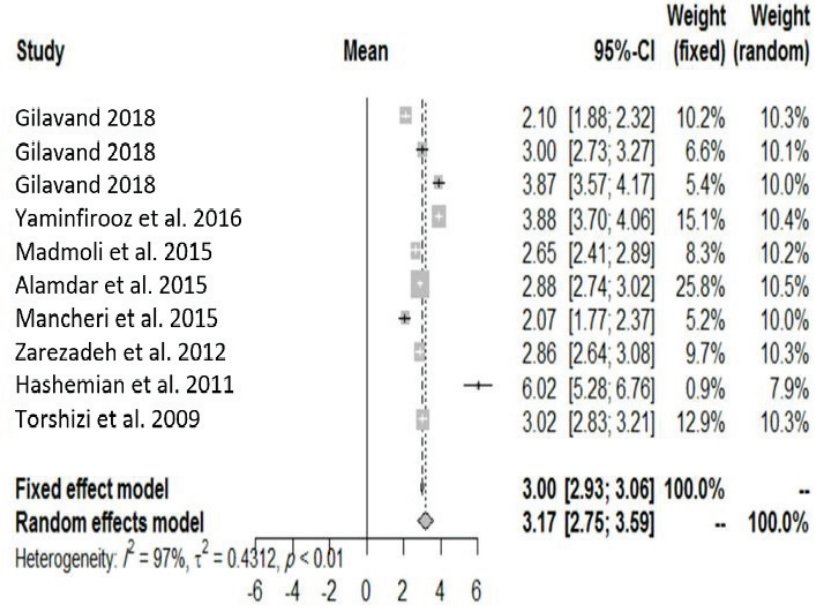

Figure 8. Mean of students' Note-taking in Iranian medical universities

\section{Physical conditions}

In this area, the physical environment of the students' location, such as noise, heat, ventilation, lighting, and other physical factors, are considered. The highest average score for physical 
conditions was from the study by Yaminfirooz et al. [20], done in 2016 among students of Babol University of Medical Sciences in northern Iran, with a value of 9.09, while the lowest average score of physical conditions was from the study by Hashemian et al. [26], performed in 2011 among students of Isfahan University of Medical Sciences in central Iran, with a value of 5.74 . The combined meta-analysis or estimation of the mean effects as a result of a study of the 10 articles $(7.60,6.27$ : $95 \% \mathrm{Cl})$ was calculated as 6.94 (Figure 9).

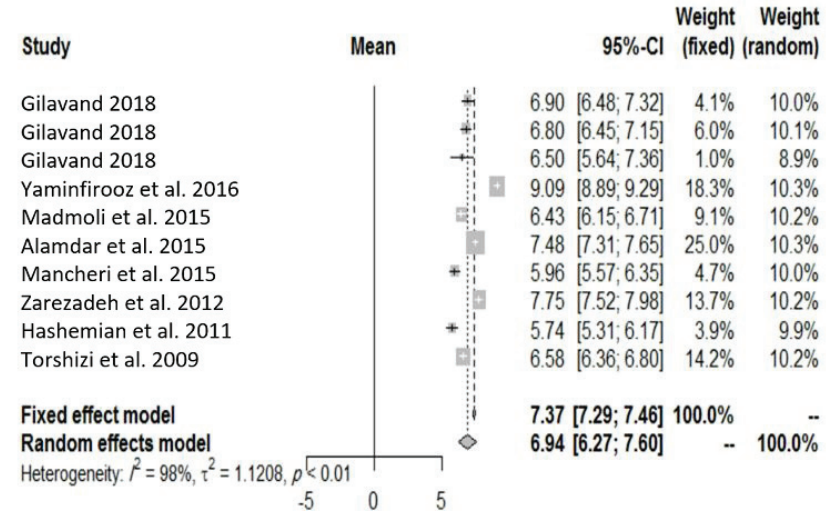

Figure 9. Mean of students' Physical conditions in Iranian medical universities

\section{Reading Capability}

Reading capability studies prioritization when reading content, the accuracy of reading, and the chosen reading method based on the importance of the topic being studied. According to several studies, the highest average reading ability score was noted in the study by Yaminfirooz et al. [20], done in 2016 among students of Babol University of Medical Sciences in northern Iran, with a value of 11.05; the lowest average of reading ability was reported in Hashemian et al.'s study [26], carried out in 2011 among students of Isfahan University of Medical Sciences in central Iran, with a value of 5.47. The combined metaanalysis or estimation of the mean effects by studying the ten articles $(9.05,7.22: 95 \% \mathrm{Cl}$ ) was calculated as 8.14 (Figure 10).

\section{Study}

Gilavand 2018

Gilavand 2018

Gilavand 2018

Yaminfirooz et al. 2016

Madmoli et al. 2015

Alamdar et al. 2015

Mancheri et al. 2015

Zarezadeh et al. 2012

Hashemian et al. 2011

Torshizi et al. 2009

\section{Fixed effect model}

Random effects model

Heterogeneity. $r^{2}=99 \%, \tau^{2}=2$

$$
\begin{array}{ccccc}
2.1207, p<0.01 & & 1 & \\
-10 & -5 & 0 & 5 & 10
\end{array}
$$

Figure 10. Mean of students' Reading capability in Iranian medical universities

\section{Discussion}

In the current study, 13 articles were analyzed, as a result of which 2,665 students who were studying at one of the Iranian medical universities from 2006 to 2018 were evaluated based on the Palsane and Sharma Study Habit Inventory (PSSHI). The total score of students' study habits was 49.03 out of a maxi- mum score of 90 , and according to the score of the questionnaire, this value is evaluated as moderate or relatively favorable. Likewise, eight areas of students' study habits were calculated separately: time budgeting was 5.61 out of a maximum score of 10 , physical conditions was 6.94 out of a maximum score of 12 , reading capability was 14.8 out of a maximum score of 16 , note-taking was 3.17 out of a maximum score of 6 , learning motivation was 6.93 out of a maximum score of 12 , memory was 4.61 out of a maximum score of 8 , taking exams was 9.92 out of a maximum score of 20 , and health was 3.23 out of a maximum score of 6 . Among the eight components examined, the score of taking exams was 9.92 out of a maximum score of 20 and was not only the lowest value, but also the only one that was less than $50 \%$. Taking examinations considers factors such as exam anxiety, the student's sleep status during the exam, the way of answering questions during the exam, time management based on the type and number of exam questions, reading the notes taken before the exam, and arranging the exam questions.

In the area of Taking exams (which had the lowest score in this study), several studies have explored numerous aspects, such as anxiety during tests, students' sleep status during exams, and the method of evaluating students' performance independently. For example, "studies have shown that there is an inverse relationship between test-taking anxiety and students' academic achievement, and students who have better study habits have less test anxiety" [8]. Numerous studies have shown the prevalence of test anxiety among students of Iranian medical universities [30-33]. In their study, Mohammadi and Parandin reported a high percentage of test anxiety among medical students at the Kermanshah University of Medical Sciences in western Iran [31]; likewise, Yousefi et al. found a high percentage of anxiety test among medical students of Kurdistan University of Medical Sciences Western Iran [32]. Torabi et al. studied dental students at Kerman University of Medical Sciences in central Iran and reported some degree of test anxiety [33]. Hashemi et al. indicated the number of student courses during the academic semester and the long academic semester as the main causes of anxiety in Iranian students [34]. In a review study, academic exams were mentioned as the most important cause of stress among dental students [35]. By comparison, in a study conducted in Serbia, an average level of test anxiety was reported in medical students [36]. In studies done in Greece and India, the fear of failing exams in school was reported as the main cause of stress in medical and dental students [37-38]. Afzal et al. also found test anxiety in Pakistani medical students, with a higher percentage of test anxiety among fourth- and final-year students [39].

Another significant factor in the area of Taking exams is the students' sleep status during exams. Sleep is a vital criterion for maintaining a person's physical and mental health, and any disruption to normal sleep can reduce a person's performance in addition to causing mental health problems. Several studies that have inspected the sleep status of students in Iranian medical universities during the exams indicate students' insomnia (especially on exam night) and its effect on students' mental health and academic achievement [40-45]. Uncontrolled use of the Internet and virtual social networks, communication-emotional dependence, family factors, normative pressure of friendship group, social indifference, and a sense of anonymity are the most important factors that cause delayed sleep disorders in students [45].

Another important factor that is mentioned in the area of Taking exams and may even lead to students' academic failure is the low quality of the performance evaluation methods at the end of the academic semester. Studies show that such tests as virtual tests $[46,47]$, multiple-choice tests [48], or practical tests [49] can affect the study habits of students of Iranian medical universities.

Based on the total result of this study, it can be claimed that the choice of the correct study methods by students can lead 
to their academic progress. The study done by Alimohamadi et al. revealed that correct study habits had a positive effect on the academic performance of nursing students at the Hamadan University of Medical Sciences in western Iran [21]. Gilavand's study also disclosed that good study habits, while reducing test anxiety, had a positive effect on the academic performance of medical students at Ahvaz Jundishapur University of Medical Sciences in western Iran [8]. Also, the study of Jafari et al. showed that correct study habits had a positive effect on the academic performance of students of Kermanshah University of Medical Sciences in western Iran [18]. The results of a study done by Alzahrani et al. (2018) among 257 medical students in Saudi Arabia indicated that there was a relationship between the students' study habits and factors such as study time, study materials, academic interruptions, and the students' desire to study and affect learning. The gender of the students was also a significant factor in this regard [9]. The results of a 2015 study done by Baothman et al. in Saudi Arabia showed that correct study habits had a positive effect on the academic performance of medical students [10]. Pourfeiz (2013) also in a study of 400 first-year university students at Ankara State University in Turkey found that there was a significant relationship between the students' learning habits and academic achievement. This study also revealed a significant relationship between the students' economic and social status and academic achievement [11]. Rabia et al. scrutinized the relationship between the study habits and academic performance of students who studied at two Pakistani public universities. The results showed that there was a significant relationship between the study habits and the students' academic performance [12]. The results of a study by Elche et al. (2018) carried out among 1,614 students studying at Spanish universities disclosed that there was a relationship between academic achievement and cultural leisure time and technology with reading methods, especially of a professional nature [14]. Mendezabal, in the Philippines, indicated that there is a statistically significant relationship between students' study habits and academic performance, and that the students who used appropriate study and learning methods performed better in final examinations with higher scores [13]. Rana and Kausar in a study entitled "Comparison of study habits and academic performance of white British students and British students of Pakistani descent," concluded that the English students had better study habits than Pakistani students and there was a significant difference in academic performance between the two groups. Nevertheless, it has been concluded that improving the students' reading habits will lead to their academic progress and success [15]. The results of Liles et al.'s study conducted in the United States indicated that successful medical students use certain study habits that they need to share with other students [16]. Likewise, to improve the study habits of students of Iranian medical universities, several interventional studies have been conducted. The results of two semi-experimental studies conducted separately by a designer of an educational application also disclosed that the mobile educational application "Students' appropriate methods of studying and learning" had a positive effect on improving learning and the study habits and academic achievement of the students researched. In the first study on students of different fields from the Ahvaz Jundishapur University of Medical Sciences in southwestern Iran, the status of their study habits (with a maximum score of 90 ), upgraded from a relatively favorable or moderate state (52.5) to favorable (76.58) [18]. In addition, the second study indicated that the application had a positive effect on the academic achievement of BA students in radiology and that the average scores at the end of the academic semester of the intervention group students (which was considered an indicator of their academic progress) increased from an average of 14.65 to 16.95 (with a maximum mean score of 20) [50]. The findings of a study conducted among the operating-room students of Ilam University of Medical Sciences in western Iran also demonstrated that after the educational intervention in the form of an academic workshop on learning skills during the academic semester, the average score of the students in the intervention group increased from 15.05 to 15.75 (with a maximum score of 20) at the end of the academic semester [51]. The results of a study conducted among nursing students at the Gorgan University of Medical Sciences in northern Iran also revealed that Team-Based Learning had a positive effect on students' study habits as it increased from 45.23 to 48.75 [23]. The results of a study by Montrieux et al. indicated that creating diversity in the education style and use of smart tablets, due to their special appeal, emotionality, and diversity can be considered to improve learning in educational systems [52].

The criterion for assessing students' study habits in this study was the Palsane and Sharma Study Habit Inventory (PSSHI). Trockels et al. criticized this questionnaire in their research and believe that this tool needs to be revised and modified, especially its "welfare (health)" area so that it can more accurately evaluate students' reading habits [53].

\section{Conclusions}

In Iran, medical, dental, pharmaceutical, and other related fields are among the most popular, because they have a better labor market prospects than other fields of study. Subsequently, usually "talented and elite people enter medical universities by choosing these fields (although some people who may not be elite, also enter these universities using special quotas)." Since these fields of study are related to people's health, it is expected that these students will have study habits that are better and higher than average, and this point should be considered by the Ministry of Health and Medical Education of Iran. Universities can assess their students' study habits before they start university, and if necessary, improve the study habits by performing some educational interventions, such as organizing training courses and using mobile educational applications.

Acknowledgements. The authors thank the Ahvaz Jundishapur University of Medical Sciences for grants.

Source of funding: This research was derived from the research project approved by Deputy of Research and Technology of Ahvaz Jundishapur University of Medical Sciences in Iran with number 330097947 and Ethics Code of IR.AJUMS.REC.1399.553. Conflicts of interest: The authors declare no conflicts of interest.

\section{References}

1. Kooshan M, Heydari A. Study habits in students of Sabzevar School of medical sciences. Quarterly Journal of Sabzevar University of Medical Sciences 2007; 13(4): 185-189.

2. Donker AS, Boer $\mathrm{H}$ de, Kostons D, et al. Effectiveness of learning strategy instruction on academic performance: a metaanalysis. Educ Res Rev 2014; 11: 1-26.

3. Derossis AM, Rosa D Da, Schwartz A, et al. Study habits of surgery residents and performance on American Board of Surgery in Training examinations. Am J Surg 2004; 188(3): 2306.

4. Chen M-L. Influence of grade level on perceptual learning style preferences and language learning strategies of Taiwanese English as a foreign language learners. Learn Individ Differ 2009; 19(2): 304-308. 
5. Poscia A, Frisicale ME, Parente P, et al. Study habits and technology use in Italian university students. Ann Ist Super Sanità 2015; 51(2): 126-130.

6. Gallardo-Echenique E, Bullen M, Marqués-Molías L. Student communication and study habits of first-year university students in the digital era. Can J Learn Technol 2016; 42(1):1-21.

7. Hosseini SM, Amery H, Emadzadeh A, et al. Dental students' educational achievement in relation to their learning styles: a crosssectional study in Iran. Glob J Health Sci 2015; 47(5): 152-158.

8. Gilavand, A. Evaluation of study habits among general medical students and its relation with test anxiety in Ahvaz Jundishapur University of Medical Sciences, Southwest of Iran. JRMDS 2018; 6(5): 240-245.

9. Alzaharani SS, Soo Park Y, Tekian A. Study habits and academic achievement among medical students: a comparison between male and female subjects. Med Teach 2018; 40(1): S1-S9.

10. Baothman A, AlJefri H, Agha S, et al. Study habits of health science students at King Saud bin Abdulaziz University for Health Sciences, Jeddah, Saudi Arabia. SAGE Open 2018; 8(2): 26-40.

11. Pourfeiz J, Mohamadi Behjoo B. A study of study habits and academic achievement among Turkish ELT students. Procedia-Social and Behavioral Sciences 2013; 70(1): 1216-1223.

12. Rabia M, Mubarak N, Tallat $\mathrm{H}$, et al. A study on study habits and academic performance of students. International Journal of Asian Social Science 2017; 7(10): 891-897.

13. Mendezabal MJN. Study habits and attitudes: the road to academic success. Open Science Repository Education 2018; e70081928, doi: 10.7392/Education.70081928.

14. Elche M, Sanchez-Garcia S, Yubero S. [Reading, leisure and academic performance in university students of the socioeducational area]. Educacion XX1 2018; 22(1): 215-237 (in Spanish).

15. Rana SA, Kausar R. Comparison of study habits and academic performance of Pakistani British and white British Students. PJSCP 2011; 9: 21-26.

16. Liles J, Vuk J, Tariq S. Study habits of medical students: an analysis of which study habits most contribute to success in the preclinical years. MedEdPublish 2018; 7(1): 61, doi: 10.15694/mep.2018.0000061.1.

17. Gilavand, A. Investigating the study habits of dental students of Ahvaz Jundishapur University of Medical Sciences, Southwest of Iran. Educ Res Med Sci 2019; 8(1): e85884.

18. Gilavand, A. Investigating the effect of using mobile educational application of study habits on improving students' awareness concerning proper study habits. JRMDS 2018; 6(5): 273-277.

19. Jafari H, Aghaei A, Khatony A. Relationship between study habits and academic achievement in students of medical sciences in Kermanshah - Iran. Adv Med Educ Pract 2019; 10: 637-643.

20. Yaminfirooz M, Yadollahpour MH, Esbakian S. [Reading habits and skills among students: a case study of Babol University of Medical Sciences]. Educ Strategy Med Sci 2019; 12(5): 1-8 (in Persian).

21. Alimohamadi N, Dehghani M, Almasi S, et al. Relation study between study habit and academic performance of nursing students in Hamadan. Pajouhan Scientific Journal 2018; 16(3): 29-38, doi: 10.18869/psj.16.3.29.

22. Madmoli Y, Aslani A, Ahmadi Y, et al. Study habits and related factors in students of Nursing and Midwifery College of Dezful University of Medical Sciences in 2015. IJNR 2017; 12(5): 27-34.

23. Alamdar H, Bakhtar M, Sheikh Fathollahi M, et al. A survey on the study habits in students of Rafsanjan University of Medical Sciences in 2015. JRUMS 2017; 16(2): 155-168.

24. Mancheri H, Kolagari S, Modanloo M, et al. Effect of team-based learning on study habits of nursing students. J Res Dev Nurs Midw 2018; 15(1): 17-24.

25. Zarezadeh Y, Rasolabadi M. Students' study skills and habits and some related factors in Kurdistan University of Medical Sciences. J Med Educ Dev 2015; 8(17): 29-37.

26. Hashemian M, Hashemian A. Investigating study habits of library and information sciences students of Isfahan University and Isfahan University of Medical Sciences. IJME 2014; 14(9): 751-757.

27. Torshizi M, Varasteh S, Poor Rezaei Z, et al. Study habits in students of Birjand University of Medical Sciences. IJME 2013; 12(11): 866-876.

28. Fereidouni Moghadam M, Cheraghian B. Study habits and their relationship with academic performance among students of Abadan School of Nursing. Strides Dev Med Educ 2009; 6(1): 21-28.

29. Gilavand A, Maraghi E. Assessing the quality of educational services of Iranian universities of medical sciences based on SERVQUAL's Evaluation Model: a systematic review and meta-analysis. Iran J Med Sci 2019; 44(4): 273-284.

30. Ramezani J, Hossaini M, Ghaderi M R. The relationship between test anxiety and academic performance of Nursing and Emergency Medical Technician students. Educ Strategy Med Sci 2016; 9(5): 392-399.

31. Mohammadi MM, Parandin S. Evaluation of exam anxiety level among Kermanshah University of Medical Sciences students and its Association with demographic characteristics in 2014. J Med Edu Dev 2015; 10(3): 227-236.

32. Yousefi F, Habibi S, Mohammadkhani M. Test anxiety level in medical students and its relationship with sexuality. Educ Strategy Med Sci 2013; 6(3): 141-145.

33. Torabi M, Haghani J, Karimi Afshar M, et al. Exam anxiety among dental students of Kerman University of Medical Sciences, Iran, in 2013. Strides Dev Med Educ 2015; 11(4): 534-541.

34. Hashemi GS, Sanagoo A, Azimi M. The relationship between study habits and ambiguity tolerance with hyperactivity in graduate students Azad University of Gorgan. DSME 2017; 4(2): 15-26.

35. Alzahem AM, Molen HT van der, Alaujan AH, et al. Stress among dental students: a systematic review. Eur J Dent Educ 2011; 15(1): 8-18.

36. Latas M, Pantić M, Obradović D. Analysis of test anxiety in medical students. Med Preg/ 2010; 63(11-12): 863-866.

37. Pradeep ST, Mathur A, Gupta R, et al. Assessment of stress level among dental school students: an Indian Outlook. Dent Res J (Isfahan) 2011; 8(2): 95-101.

38. Maimanee TA. The impact of exam anxiety on the level of triglycerides in university female students. J Egypt Soc Parasitol 2010; 40(1): 259-270.

39. Afzal H, Afzal S, Siddique SA, et al. Measures used by medical students to reduce test anxiety. J Pak Med Assoc 2012; 62(9): 982-986.

40. Abbaszadeh $\mathrm{M}$, Piryalghon S, Musavi A. Factors underlying the late sleep among female students of the dormitory of Tabriz University Based on grounded theory. Journal of Applied Sociology the University of Isfahan 2017; 28(1): 1-18.

41. Panahi S, Jafari A, Hajaghazadeh M. Sleep quality in the public health students of Urmia University of Medical Sciences in 2017. Nurs Midwifery J 2019; 17(4): 282-291.

42. Dehdari T, Taatti R, Chaboksavar F. The relationship between sleep quality and psychological condition in college students. RSJ 2016; 2(1): 1-9. 
43. Mansouri A, Mokhayeri Y, Mohammadi Farrokhran E, et al. Sleep quality of students living in dormitories in Tehran University of Medical Sciences (TUMS) in 2011. IRJE 2012; 8(2): 71-82.

44. Ghoreishi A, Aghajani AH. Sleep quality in Zanjan university medical students. Tehran Univ Med J 2008; 66(1): 61-67.

45. Shakerinia I. The relationship between sleep status and Internet use among college students. Jour Guilan Uni Med Sci 2015; 24(95): 7-15.

46. Azimi SA, Zamani BE, Soleimani N. Investigating the quality of assessment system of students' performance in virtual education in Iran and Russia. Educ Strategy Med Sci 2016; 9(3): 214-223.

47. Seraji F, Movahedi R, Siahat Khah M. An investigation of Iranian Virtual Universities teachers' skills in teaching these courses. TEJ 2014; 9(1): 37-25.

48. Kojury J, Rivaz S, Amini M, et al. Assessment of educational group's status based on types of evaluation methods of medical students at the Shiraz University of Medical Sciences 2014. MEDEDJ 2017; 5(1): 7-13.

49. Jasemi M, Ahangarzadeh Rezae SI, Hemmati M, et al. Evaluation of the effect of evaluation using the direct observation skills (DOPS) and traditional methods on nursing students' clinical skills learning, 2016. RJMS 2019; 25(10): 1-9.

50. Gilavand A, Fattahi Asl J, Kameli M. Investigating the effect of using the mobile educational app for appropriate methods of study and learning on students' educational achievement. FMEJ 2019; 9(1): 25-29.

51. Otaghi M. Effect of teaching academic skills on academic achievement in Medical Emergency students. Educ Strategy Med Sci 2015; 8(5): 269-274.

52. Montrieux H, Courtois $\mathrm{C}$, Raes A, et al. Mobile learning in secondary education: teachers' and students' perceptions and acceptance of tablet computers. IJMBL 2014; 6(2): 26-40.

53. Trockels A, Smith E, Velazquez-Pimentel D. Relationship between study habits and academic achievement in students of medical sciences in Kermanshah - Iran [Letter]. Adv Med Educ Pract 2019; 10: 841-842.

Tables: 1

Figures: 10

References: 53

Received: 02.06.2020

Reviewed: 15.03 .2021

Accepted: 11.05 .2021

Address for correspondence:

Abdolreza Gilavand, PhD, Assistant Professor

Department of Community Medicine, School of Medicine

Ahvaz Jundishapur University of Medical Sciences

Ahvaz

Iran

Tel.: +98 9166423747

E-mail: gilavand_a@ajums.ac.ir, gilavanda@gmail.com 